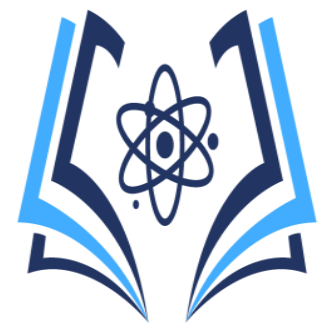

\title{
Patología respiratoria por Covid 19 severa y protocolo de reanimación cardiopulmonar en paciente adulto
}

\section{Severe Covid 19 respiratory disease and cardiopulmonary resuscitation protocol in an adult patient}

\author{
Dra. Johanna Mabel Sánchez Rodríguez \\ Universidad Estatal del Sur de Manabí / Universidad Laica Eloy Alfaro de Manabí \\ johanna.sanchez@unesum.edu.ec/johanna.sanchez@uleam.edu.ec, Código Orcid 0000-0002-7799-1151 \\ Contacto: johanna.sanchez@unesum.edu.ec
}

Recibido: 29-09-2019

Aprobado: 15-12-2019

\section{Resumen}

La pandemia por Covid19 a nivel mundial y la falta de un tratamiento curativo para el proceso además del desconocimiento de la enfermedad como tal por ser de tan reciente evolución es un tema relevante para estudio de revisión bibliográfica en los estudiantes de pregrado para describir la problemática, causa y efecto de esta afección respiratoria. Cada día las cifras van incrementando de manera exponencial por diferentes factores sociales, el desconocimiento científico del origen del Covid19, modo de trasmisión, reservorio, su alto nivel de contagio y la deficiente capacidad de respuesta ante la emergencia sanitaria principalmente en los países latinos entre ellos Ecuador, que desde que presentó su primer caso exportado se pudo evidenciar el debilitado Sistema de Salud Pública.

Por medio una exhaustiva revisión bibliográfica se ha analizado la patología respiratoria por Covid-19 severo y protocolo de reanimación cardiopulmonar en paciente adulto, se explican los factores relacionados al distress respiratorio en situación grave del paciente Covid y además de diferencian los protocolos de acción del personal de salud frente al paro cardio respiratorio habitual y las particularidades del paciente. Se determina la importancia de las condiciones hospitalarias para una correcta asistencia de la patología y se concluye que existen diferencias significativas en la actuación de emergencia.

Palabras clave: Pandemia, reanimación cardiopulmonar, distress respiratorio, protocolos de manejo.

Summary

The Covid19 pandemic worldwide and the lack of a curative treatment for the process in addition to the ignorance of the disease as such because it is of such recent evolution is a relevant topic for a bibliographic review study in undergraduate students to describe the problem, cause and effect of this respiratory condition. Every day the figures are increasing exponentially due to different social factors, scientific ignorance of the origin of Covid19, mode of transmission, reservoir, its high level of contagion and the poor capacity to respond to the health emergency, mainly in Latin countries among them. Ecuador, that since it presented its first exported case, the weakened Public Health System could be evidenced.

Through an exhaustive bibliographic review, the respiratory pathology due to severe Covid-19 and the protocol of cardiopulmonary resuscitation in an adult patient have been analyzed, the factors related to respiratory distress in serious situation of the Covid patient are explained and in addition to differentiating the action protocols of the personnel of health against the habitual cardiorespiratory arrest and the particularities of the patient. The importance of hospital conditions for correct care of the pathology is determined and it is concluded that there are significant differences in emergency action.

Key words: Pandemic, cardiopulmonary resuscitation, respiratory distress, management protocols.

\section{Introducción.}

Los coronavirus se descubrieron en los años 60 siendo importantes patógenos humanos y animales, provocando diferentes enfermedades que pueden ir desde un resfriado común hasta producir infecciones graves de las vías respiratorias bajas tales como la neumonía. Hasta diciembre del 2019, se habían identificado seis tipos de coronavirus que causan infecciones respiratorias en los seres humanos mucho más graves incluso llegando a ser mortales, entre ellos los causantes de los dos brotes epidémicos más importantes: el SARS coronavirus que apareció 
por primera vez en el año 2002 y el MERS-CoV, que se identificó por primera vez en el año 2012 en el medio oriente. A finales de diciembre del 2019 , se identificó un nuevo coronavirus como el agente causal de un grupo de casos de neumonía idiopática en la ciudad de Wuhan, capital de la provincia de Hubei en China. La Organización Mundial de la Salud (OMS) en febrero de 2020 lo denominó como síndrome respiratorio agudo severo 2 (SARS-CoV-2) actualmente conocido como COVID-19 o el nuevo coronavirus 2019. (1) Este nuevo coronavirus se extendió rápidamente desde Wuhan, dando como resultado al inicio de una epidemia en toda China, seguida de una pandemia global, generando la emergencia sanitaria actual. Al ser una patología que recientemente apareció aún se desconoce a ciencia cierta su epidemiología, transmisión, y tratamiento.

A nivel mundial se ha informado que el número de casos confirmados por el nuevo coronavirus durante el primer semestre del 2020 se aproximan a los 9 millones de casos confirmados, todas las regiones del mundo ya han sido afectadas por este virus. Entre ellas, destaca América con > de 5 millones de contagiados. Conforme la evidencia de los datos epidemiológicos, la transmisión del COVID -19 en Ecuador ascienden a los 51 mil casos confirmados según el reporte de las infografías del Comité de Operaciones Emergentes Nacional (COE).(2)

Manabí, es la tercera provincia con más contagios por COVID - 19 según el boletín epidemiológico por provincia y sus cantones que emite el COE y el Ministerio de Salud Pública del Ecuador cohorte Febrero- junio, hay alrededor de 4 mil casos confirmados y casi 600 fallecidos por esta enfermedad.(2)

Durante esta pandemia, un alto porcentaje de los casos requieren de una unidad de cuidados intensivos debido a la gravedad que ocasiona el COVID 19 en ciertos grupos etarios que presenta colapso circulatorio y terminan en un paro cardiaco pulmonar.

El propósito de esta revisión bibliográfica es describir la actualización y establecer el protocolo de RCP para el manejo del paciente con afección grave respiratoria, que sufre una sintomatología que en su mayoría termina en paro cardiaco en el contexto de la pandemia por COVID19. El manejo del paciente de acuerdo a la Lex Artis, se tendrán en cuenta las guías de la AHA (American Heart Asociación) y de la ILCOR (International Liaison Committee on Resuscitation), así como los de reportes de RCP en posición prona, donde cada día se encuentra mayor evidencia de su utilidad. (3) Frente a un paciente que presenta paro cardio respiratorio se deberán tomar todas las precauciones del personal de salud antes de la reanimación cerebrocardio-pulmonar (RCP), puesto que, por la experiencia en China, el 79\% de los casos confirmados fueron contagiados por el $86 \%$ de pacientes que estaban asintomáticos. Es importante considerar que los pacientes con COVID19 y enfermedad cardiovascular tuvieron la tasa más alta de mortalidad (10.5\%). Las causas de estas complicaciones fueron las arritmias (16.7\%) y la lesión miocárdica aguda (7.2\%).

La situación creada por la pandemia por SARSCoV-2 ha generado nuevos escenarios que requieren modificaciones de los protocolos habituales de reanimación cardiopulmonar (RCP), manteniendo el objetivo de que aquellos pacientes que sufran una parada cardiorrespiratoria reciban la mejor atención sin que esto comprometa la seguridad de los reanimadores. (3)

Según los datos disponibles publicados por la OMS, el SARS-CoV-2 puede transmitirse principalmente entre personas a través de gotas respiratorias y del contacto. Se deben prever todos los Equipos de Protección Personal (EPP) adecuados (de acuerdo con pautas para manejo de COVID-19) en todo escenario donde pueda ocurrir un PCR. La pronta disponibilidad de EPP promoverá una demora en el inicio de las compresiones torácicas, la seguridad del equipo es una prioridad, y el uso de EPP adecuado es indispensable para el equipo que asiste a la PCR. No se debe realizar ningún procedimiento sin la instalación previa del EPP completo, incluido el inicio de las compresiones torácicas y los procedimientos en las vías respiratorias. (4)

En concordancia con la cadena de supervivencia a el PCR intrahospitalario la vigilancia estricta del paciente y la prevención del evento mediante scores, son fundamentales para mejorar la eficacia de las maniobras (preparación previa, EPP listo) optimizando el proceso, así como para determinar fehacientemente la orden de no resucitación (DNR).

En América los países que lideran los contagios y muertes a causas del Covid son: Estados Unidos, y Brasil, con más de 1 millón de contagiados, en Ecuador las cifras van en aumento gracias a la disposición de dominio de la situación real (5)

\section{Problematización.}

La enfermedad causada por el SARS- CoV- 2 (COVID19), declarada como pandemia por la Organización Mundial de la Salud el 11 de marzo de 2020, surge por primera vez en la ciudad de Wuhan, provincia de Hubei China y con ella el inicio de un sin número de investigaciones, ensayos clínicos y planes de contingencia e intervenciones para lograr el manejo adecuado de la afección clínica altamente contagiosa y evitar la propagación de esta nueva patología respiratoria. (4)

La magnitud de esta problemática, ha generado pánico global ante la falta de conocimiento, comprensión de los patrones de transmisión, el 


\section{HIGIA DE LA SALUD}

manejo de las características clínicas y los factores de riesgos que desarrolla esta afección respiratoria, desencadenando el colapso de los sistemas de salud, economía, educación y las actividades de la vida diaria. (4)

La comunidad mundial de la salud reconoce lo necesario que ha sido desarrollar investigaciones estandarizadas y la compilación de datos para documentar la historia natural de la enfermedad y sus avances, con el objetivo de ir ampliando los reducidos conocimientos que se tienen de esta nueva morbilidad. (6) Según datos oficiales de la Organización Mundial de la Salud durante el primer semestre del 2020, se reportan más de 8,8 millones de casos confirmados y más de 400 mil muertes a causa de la pandemia. (7)

La evolución de este tipo de coronavirus ha sido realmente impactante, su alto grado de contagio, tasa de letalidad y mortalidad que a inicios de la misma fue subestimada precisamente por el desconocimiento, u omisión de la información sobre el nuevo SARS- Cov-2, sumado a las diferentes condiciones sociales y culturales de la población mundial, desencadenó el aumento exponencial de los casos de Covid 19 que tuvieron origen en China con más de 84 mil casos, luego España > 246 mil) Italia > 230 mil países europeos más azotados por la pandemia; (3) en la actualidad América es el continente con más casos confirmados y muertes por Covid, liderando esta nómina Estados Unidos con > 2 millones de casos confirmados y más de 119 mil muertes, seguido de Brasil > 1 millón de casos confirmados y 50 mil muertes, Rusia con más de 583 mil casos y la India con más de 400 mil casos. (7)

Según el informe que emite la OMS en su "Panel de la enfermedad de coronavirus (COVID 19)" donde realiza una comparación de casos confirmados por región, donde podemos verificar el impacto que ha tenido el Covid en la región de América; los datos son los siguientes: Américas > 4.3 millones de casos; seguido por Europa > 2.5; Mediterráneo oriental > 900 mil; Sudeste de Asia $>600$ mil; África > 200 mil; Pacífico oeste > 200 mil. (5)

La severidad de la presentación clínica del paciente con covid varía de caso en caso. A inicio del mes de Abril la OMS declara que aproximadamente el $6 \%$ de los pacientes derivan a un estado crítico, que desencadena a la dificultad respiratoria conllevando en la mayoría de los casos episodio de paro cardio respiratorio, donde el personal de salud debe aplicar los protocolos de reanimación establecidos para el manejo de dicha situación. Protocolos que han sido forzados a variar de acuerdo a las complicaciones generadas, a partir de la aplicación de las mismas. (4)

Las intervenciones en el manejo del paciente con Covid, han estado en constante evolución y modificación, de acuerdo a los resultados
ISSN 2773-7705

Periodo. Julio - Diciembre 2019

Vol. 1, Nro. 1, Publicado 2019-12-31

obtenidos con base a la evidencia y la variación que ha presentado la patología desde el inicio de la pandemia hasta la actualidad.

Los tratamientos que se aplicaron a inicios de esta pandemia van desde la administración de Cloroquina un antinflamatorio usado habitualmente para combatir la malaria, luego el Remdesivir que se desarrolló para el Ébola, En un estudio estándar publicado por la revista Research Cell que midió los efectos de estos compuestos sobre la citotoxidad, el rendimiento del virus y las tasas de infección de 2019- nCoV en ese entonces, evaluaron la eficacia de los compuestos mediante la cuantificación de los números de copias virales a las $48 \mathrm{~h}$ después de la infección in vitro de células sanas con las del covid mediante prueba RT-PCR cuantitativa en tiempo real, se demostró una reducción de la carga viral; también mencionan el estudio y la aplicación de ensayos clínicos basados en la administración de un anti protozoario muy común la Nitazoxanida que contiene un potencial antiviral contra una amplia gama de virus, incluidos los coronavirus humano y animales, inhibiendo el virus a una concentración micromolar baja. (8)

El uso de la azitromicina combinada con hidrocloroquina también formó parte del protocolo de tratamiento en algunos países, en pacientes con agravamiento de la enfermedad, actualmente la Universidad de Oxford lidera un estudio llamado RECOVERY, donde dan los primeros resultados que el uso de la dexametasona ha reducido un tercio la mortalidad en pacientes ventilados graves por Covid, donde están involucrados 11.500 pacientes de más de 175 hospitales del Reino Unido. (9)

Aunque la sociedad médica no cuenta con un tratamiento totalmente eficaz para poder controlar la sintomatología que cursa las personas que contraen este virus catalogado altamente contagioso, es preciso connotar los esfuerzos que se están realizando por mejorar los protocolos de atención, diagnóstico, y tratamiento de la enfermedad.

En Ecuador la pandemia inició con gran fuerza, y al igual que otros países por el desconocimiento de la gravedad del asunto, sumado a un sistema de salud debilitado por falta de infraestructura, insumos, equipos de atención, falta de coordinación de las autoridades pertinentes y diferentes factores socioeconómicos, el índice de contagios se incrementó rápidamente, dejando evidenciar la vulnerabilidad de las diferentes aristas que conforman nuestro País con > 50 mil casos confirmados y $>$ de 4 mil muertes. (10)

Las provincias más afectadas por el Covid 19 son Guayas > 14 mil; Pichincha > 6 mil, Manabí > 3 mil; Los Ríos > 2 mil, siendo la ciudad de Guayaquil el epicentro de máximo contagio con 9.950 casos. (11) 


\section{HIGIA DE LA SALUD}

Portoviejo, la capital manabita con > de 900 casos es el foco de concentración de confirmados según datos infográficos del COE Nacional, y con ello la desesperación, por la crisis económica, social y sanitaria son la fórmula perfecta que causa el incremento exponencial de los casos de contagio y muertes, como lo confirman los indicadores. (11) La realidad de Ecuador con su alto índice de contagios y muertes están relacionados a la falta de un tratamiento específico y la desobediencia de las disposiciones gubernamentales en cuanto a las normas de bioseguridad, confinamiento, y distanciamiento que debe cumplir la población, haciendo caso omiso parcial a todas las recomendaciones que emiten, esto sumado al déficit de camas en las unidades de cuidados intensivos, ventiladores mecánicos y equipos de protección personal que dieron como resultado la exposición directa del personal de salud que fallecieron a causa del Covid 19.

\section{OBJETIVOS}

Objetivo general

- Analizar patología respiratoria por Covid-19 severo y protocolo de reanimación cardiopulmonar en paciente adulto.

\section{Objetivos específicos}

- Describir la fisiopatología de la afección respiratoria severa por Covid y sus determinantes.

- Explicar los factores relacionados al distress respiratorio en situación grave del paciente Covid.

- Diferenciar el protocolo de acción del personal de salud frente al paro cardio respiratorio habitual y las particularidades del paciente con sospecha o confirmatorio para Covid

\section{Metodología}

El presente estudio se realizó mediante revisión bibliográfica-descriptiva tomada de fuentes confiables, con base a la evidencia científica, en cuánto el origen y tratamiento de esta problemática emergente de Salud Pública e importancia mundial.

\section{Resultados}

- Se describió la fisiopatología del SARSCoV-2 (COVID19) determinando los diferentes factores predisponentes de contagio, su alto índice de mortalidad, letalidad, y el impacto social que ha tenido desde el inicio de esta pandemia

- Se explicó detalladamente lo factores relacionados a la de evolución desfavorable o complicación de la enfermedad en estadíos de situación grave del paciente con covid, mediante la revisión bibliográfica de algunas fuentes confiables, tales como estudios y
Periodo. Julio - Diciembre 2019

Vol. 1, Nro. 1, Publicado 2019-12-31

seguimientos de casos, donde revelan que los medios de defensa del cuerpo aportan al agravamiento de la persona, puesto que activan de manera desproporcionada la respuesta inflamatoria en cascada de las citoquinas provocando edema de las vías respiratorias inferiores, consecutivamente el distress respiratorio, complicaciones cardiovasculares y procesos trombolíticos desencadenando al paro cardio respiratorio.

- Se diferenció el protocolo de acción del personal de salud ante la reanimación cardio pulmonar en el paciente adulto con Covid 19, tomando en cuenta que los protocolos de RCP instaurados en nuestro medio territorial, están respaldados bajo las guías de la ASOCIACIÓN AMERICANA DEL CORAZÓN con la particularidad de que en los pacientes positivos o con sospechas de la afección respiratoria, resaltando aspectos relevantes como el omitir las compresiones directas al paciente iniciando directamente la RCP con la desfibrilación; hay que evitar vías invasivas donde se requiera el uso de bombonas que generen aerosoles potencialmente contagiosos; ningún personal de salud procederá al inicio de RCP, sin el correcto uso del Equipo de Protección Personal (EPP) respectivamente. Y una vez declarado el descenso de un paciente se debe seguir los lineamientos emitidos por el MSP, que dispone el embalaje del occiso de manera inmediata sin retirar ningún dispositivo invasivo, catéter, vendaje etc.

\section{Recomendaciones.}

- Una vez concluido este trabajo hemos podido identificar las diferentes circunstancias en que un paciente que contrae este tipo de virus, recientemente conocido, es relevante e inexcusable no estar a la vanguardia de la información pertinente que se genera en base a la evidencia científica y los diferentes estudios que se están dando.

- Se ha determinado que los protocolos para realizar la reanimación cardio respiratoria en pacientes con Covid 19, no tiene variación relevante simplemente son particularidades que deben aplicarse al momento de realizar este proceso tales como: no proceder si no estoy debidamente equipado.

Al realizar el manejo de vía aérea avanzada es necesario contar con los insumos correspondientes incluso la Aero cámara de intubación precoz. 
Colaboradores de la Investigación:

Moreira Zavala Jair; Gómez María Belén; Bailón Mera Valeria; Pincay Cardona Lady; Saltos Pincay Dennise; Zamora Pozo Josselyn; Giler Párraga José David; Villacreses Cantos Kevin; Yumbo Santana Yossenka. Estudiantes de la Carrera de Enfermería de la Universidad Estatal del Sur de Manabí.

\section{Bibliografía}

1. WHO. Etiología de los nuevos coronavirus 2019. 2020 marzo.

2. Ecuador MdSPd. Coronavirus Covid 19. ; 2020 marzo.

3. CLASA. Reanimación Cardiopulmonar en pacientes con Covid19 Buenos Aires; 2020.

4. Who Health Organization. Brotes por enfermedad de coronavirus Covid 19. ; 2020.

5. Organización Panamericana de Salud. Situación de COVID 19 en la región de las Américas. [Online]. 2020. Available from: https://www.paho.org/es/temas/coronavirus/brote-enfermedad-porcoronavirus-covid-19.

6. OMS. Comparación de casos. Actualización de casos COVID 19. Organización Mundial de la Salud; 2020.

7. Jhon Hopkins University Medicine. Coronavirus Resource Center. [Online]. 2020 [cited 2020 Junio 22. Available from: https://coronavirus.jhu.edu/map.html.

8. Wang M, Cao R, Leike Zhang XY. Remdesivir y Cloroquina inhiben eficazmente el SARS- CoV-2. Research Cell. 2020 febrero 4.

9. Medscape. Resultados preliminares del estudio RECOVERY. Medscape. 2020 junio 17.

10. INSPI. Realidad en el Ecuador. Informativo. Quito: Instituto Nacional de Investigación en Salud Pública; 2020.

11. Nacional C. Infografía Nacional de Covid19. Actualización de datos. Comité de Operaciones Emergentes; 2020.

12. BMJ. Enfermedad de Coronavirus. Best Practice. 2020 abril.

13. Sanitarias CdCyA. Enfermedad por coronavirus. Científica- Técnica. Dirección General de Salud Pública, Calidad E Innovación, CCAS; 2020.

14. fisterra.com. Enfermedad por coronavirus 2019 (COVID-19). Fisterra. 2020 Mayo 27.

15. Wang YT, Landeras S, Hsieh LE, Nava JAR. Trends in Microbiology. Best of Cell. 2020 Mayo 19.

16. Yin S, Huang M, Li D, Tang N. Diferencia de las características de la coagulación entre la neumonía severa inducida por SARS-CoV2 y no SARS-CoV2. Pubmed. 2020 abril 3.

17. Pubmed.gov. Epidemiología y patogénesis del brote de la enfermedad por coronavirus (COVID-19). Pubmed. 2020 mayo.

18. Vivas D, Roldan V,'AEP. Recomendaciones sobre el tratamiento antitrombotico durante la '. Revista Española de Cardiología. 2020 abril 14.

19. nejm.org. Características clínicas de la enfermedad por coronavirus 2019 en China. New England Journal of Medicine. 2020 febrero 28.

20. elsevier.com. Epidemic Characteristics of 2019-nCoV. Elsevier. 2020 febrero.

21. OMS. Manejo clínico de la infección respiratoria aguda. Orientaciones Provisionales. Word Health Organization; 2020. 
22. Ecuador MdSPd. LINEAMIENTOS PARA EL DIAGNÓSTICO Y MANEJO DE. Protocolo. MSP; 2020.

23. Recomendaciones sobre Reanimación Cardio Pulmonar en pacientes con Covid 19. Medicina Intensiva. 2020 junio 13.

24. MSP. Actualización de casos Covid 19. Reportes epidemiológicos. Quito: Ministerio de Salud Pública; 2020.

25. Myint DATySH. Microbiología médica S B, editor.; 1996. 